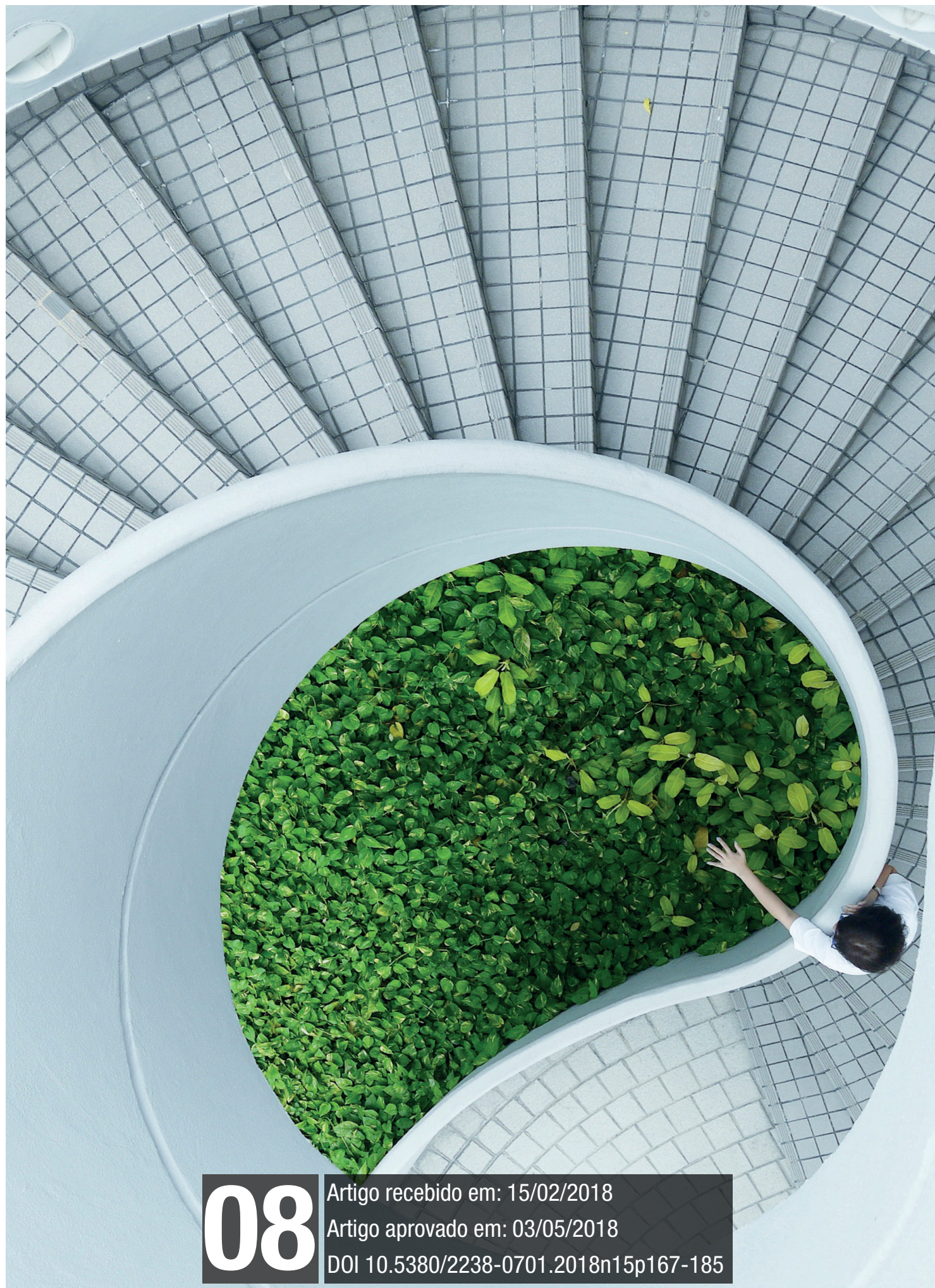


Linguagem. Sustentabilidade. Agência. Identidade. Rio+20. 


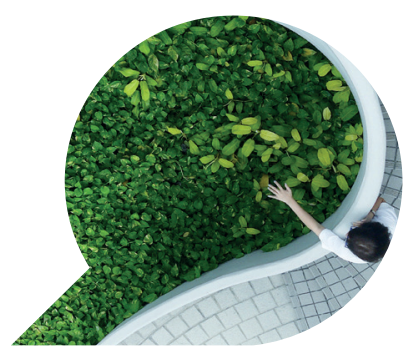

\section{Da agência à sustentabilidade: linguagem e prática social em 'Rio+20'}

De la agencia a la sostenibilidad: lenguaje y práctica social en 'Río+20'

From the agency to sustainability: language and social practice in 'Rio+20'

\section{ANTONIO NILSON ALVES CAVALCANTE ${ }^{1}$}

\section{DINA MARIA MARTINS FERREIRA ${ }^{2}$}

Resumo: Neste artigo, propomos estabelecer esse mesmo percurso teórico, a partir do ponto de convergência transdisciplinar dos estudos da linguagem, articulando diferentes autores, como Martins Ferreira (2017), Plaza Pinto (2017), Hall (2000), a fim de compreender como conceitos tão caros a esse campo de estudo podem contribuir com o panorama presente diante da sustentabilidade. Apresentamos inicialmente a problemática do

1 Pós-Graduando do Programa de Pós-Graduação em Linguística Aplicada, Universidade Estadual do Ceará/UECE.

2 Pós-douramento $\left(2^{\circ}\right)$ em Ciências Sociais pela Université Paris V, Sorbonne em co-tutoria com o Instituto de Estudos da Linguagem, Unicamp (2009-2010); pós-doutoramento (1ํㅡ) em Pragmática pela Unicamp (2002-2003); doutorado pela UFRJ (1995). Professora visitante e pesquisadora do Programa de Pós-Graduação em Linguística Aplicada,UECE; pesquisadora do Centre d'Études sur les Actuels et le Quotidien, Paris V, Sorbonne. 
consumo (BAUDRILLARD, 2005; DOUGLAS \& ISHERWOOD 2009; FEATHERSTONE (1995), MACCRAKENK, 2003) seguida da visão de Boff (2015), Veiga (2013), para então podermos considerar como os conceitos de agência e identidade podem propiciar uma justificação teórica para práticas individuais diante de ideologias que comprometem a manutenção da natureza e ainda analisar o discurso de abertura da conferência Rio+20, no intuito de rastrearmos como a mobilização social é compreendida pela linguagem das autoridades governamentais.

Palavras-Chave: Linguagem; Sustentabilidade; Agência; Identidade; Rio+20.

Resumen: En este artículo, proponemos establecer ese mismo recorrido teórico, a partir del punto de convergencia transdisciplinaria de los estudios del lenguaje, articulando diferentes autores, como Martins Ferreira (2017), Plaza Pinto (2017), Hall (2000), a fin de comprender como conceptos tan caros a ese campo de estudio pueden contribuir con el panorama presente ante la sostenibilidad. En el presente trabajo se analizan los resultados obtenidos en el análisis de los resultados obtenidos en el análisis de los resultados obtenidos, pueden propiciar una justificación teórica para prácticas individuales ante ideologías que comprometen el mantenimiento de la naturaleza y aún analizar el discurso de apertura de la conferencia Rio+20 con el fin de rastrear cómo la movilización social es comprendida por el lenguaje de las autoridades gubernamentales.

Palabras-Clave: Lenguaje; sostenibilidad; Agencia; la identidad; Rio +20 .

Abstract: In this article, we propose to establish this same theoretical course, starting from the point of transdisciplinary convergence of language studies, articulating different authors, such Martins Ferreira (2017), Plaza Pinto (2017), Hall (2000), in order to understand how concepts so dear to this field of study can contribute with the present panorama before the sustainability. We present initially the problem of wasteful consumption BAUDRILLARD, 2005; DOUGLAS \& ISHERWOOD 2009; FEATHERSTONE (1995), MACCRAKENK, 2003), followed by Boff (2015) to Veiga (2013) and others, so we can consider how the concepts of agency 
and identity can provide a theoretical justification for individual practices in the face of ideologies that compromise the maintenance of nature and also analyze the opening speech of the Rio+20 conference, In order to trace how social mobilization is understood by the language of government authorities.

Keywords: Language; Sustainability; Agency; Identity; Rio+20. 


\section{Introdução}

A proposta desse artigo se apresenta sob a perspectiva da Linguística Aplicada, sob a égide de argumentos que ressaltam a contribuição dos estudos da linguagem e as práticas sociais, além de conceitos de identidade e de agência (MARTINS FERREIRA, 2017; PINTO, 2017; HALL, 2000), em prol de discussões sobre sustentabilidade. Para tanto, o discurso de abertura da Conferência das Nações Unidas sobre Desenvolvimento $\mathrm{Natural}^{3}$, conhecida simplesmente como Rio+20 e realizada de 13 a 22 de junho de 2012, na cidade do Rio de Janeiro, se torna nosso objeto de análise.

Estruturamos este estudo em quatro partes. Primeiro, temos algumas considerações teóricas sobre identidade, pois damos ênfase a agência individual em que o sujeito da linguagem se posiciona identitariamente; segundo, abordamoso conceito deagência, enquantoaçãotransformadora no âmbito social, no caso, na prática social da sustentabilidade; terceiro, apresentamos nuanças definidoras da sustentabilidade, entendida como conjunto de ações e processos destinados a manutenção e preservação da vida como um todo e dos ecossistemas, assim como do atendimento das necessidades atuais e futuras da humanidade, para depois levantarmos expressões linguísticas que deem conta da prática social e individual da agência neste espaço 'planetário'.

Ou seja, proferimentos institucionais, do Rio+20, com seus efeitos perlocucionais (AUSTIN, 1975) que possam gerar uma ação-agência individual, e até social, para o desenvolvimento sustentável. Deste mecanismo de análise, pressupondo a possível força de pressão da sociedade civil, apontamos, como desafio no estabelecimento de uma aliança global de sustentabilidade, a ideologia de consumo de um lado e, de outro, setores do governo e de empresas que poderão se engajarem na mudança de um paradigma ambiental em prol da natureza e da população desassistida. Afinal, está na linguagem o poder de mudança como um "espaço preenchido e preenchível por forças que não só a habitam, mas que se confrontam nela e por meio dela” (FERREIRA, 2005, p. 25).

Nossa escolha de enfatizar o consumo se deve a sua força de manutenção do status quo predatório, em detrimento da sustentabilidade. Boff, em A Opção Terra (2009), postula:

30 discurso oficial de abertura da conferência Rio+20, disponível em: http://www2.planalto. gov.br/acompanhe-o-planalto/discursos/discursos-da-presidenta/discurso-da-presidenta-darepublica-dilma-rousseff-durante-cerimonia-de-abertura-protocolar-da-conferencia-das-nacoesunidas-sobre-desenvolvimento-sustentavel-rio-20. Último acesso em: 12 jan.2018. 
Em função de um consumo irresponsável e sem cuidado, o homo sapiens introduziu uma prática de depredação sistemática dos ecossistemas. Como consequência, está ocorrendo a aceleração do processo de extinção em massa de várias espécies, num ritmo que excede de longe aquele inexorável da própria natureza. Os gases de efeito estufa são os principais causadores do aquecimento global e dos transtornos climáticos que estão afetando sensivelmente a Terra (idem, p. 25-6)

Sem dúvida, na contemporaneidade, o consumo humano é o elemento central da atividade econômica, pois gera uma produção crescente. Apesar da perspectiva de produção advinda do consumo, este autor propõe uma mudança em relação ao consumo perdulário ${ }^{4}$, uma vez que a atitude de desperdício foi o que gerou a cultura do consumismo, que deve ser rejeitada a fim de forçar os setores público (governo) e privado (empresas) a criarem medidas efetivas em prol da sustentabilidade, tal qual a tão necessária aliança global ambiental.

Sob este parâmetro, alçamos ao objetivo de avaliar a aplicabilidade da agência como contribuição ao provimento da sustentabilidade, ou seja, averiguar como o discurso oficial de abertura do Rio+20, considerado um dos maiores eventos organizado pela ONU, pode gerar sentidos de unidade política da sociedade civil, quanto à sua contribuição para a transformação social.

É bom clarificar que, na agência, as dimensões individual e social não são alheias uma a outra, e sim suplementares, fazendo diferença ao que chamamos de agência institucional (governo e empresas). E, nesse contexto, consideramos ser possível tanto a agência de resistência aos discursos mercadológicos, quanto uma agência de aderência a atitudes e comportamentos ecológicos, em direção a uma maior capilarização da própria prática política e das agendas de uma economia de fato sustentável.

Apesar de nossa proposta de aderência a atitudes e comportamentos ecológicos, não podemos deixar de lembrar que o consumo é uma questão cultural (SLATER, 2001), e que, mesmo chamado de global, a internet não deixa de ser um dos mais importantes veículos de consumos localizados, por exemplo, posso comprar uma mercadoria

4 É importante esclarecer que quando se fala em consumo perdulário, e não de um consumo produtivo, estamos nos referindo a "uma espécie de superioridade moral da produção e os seus temas - trabalho, empresa, profissão (...) É como se a produção tivesse algo de nobre e valoroso, representado o mundo verdadeiro ou a vida levada a série, e o consumo, no polo oposto, tivesse algo de fútil e superficial, representando o mundo falso e inconsequente (ROCHA, apud DOUGLAS \& ISHERWOOD, 2009, p.12). 
que é produzida exclusivamente no locus USA, pela internet - o acesso é por via global, mas o produto consumido é local.

\section{Identidade}

Optamos por abordar a questão da identidade devido ao fato de que a agência individual, e mesmo social, depende de como a identidade é construída. O conceito de identidade atrelado ao nível ideológico do consumo nos possibilita ir ao encontro das abordagens críticas da linguagem, a fim de realizar a uma investigação socialmente relevante (RAJAGOPALAN, 2003). Rajagopalan (2003) considera que se a linguística não seguir os procedimentos de questionar seus próprios conceitos básicos, ela poderá se defrontar com uma completa irrelevância e não encontrará subsídios para se adequar às novas realidades. Além disso, como aponta autores como Plaza Pinto (2017) e Hall (2000), as questões identitárias que são preementes nas relações sociais perpassam as práticas linguisticas, haja vista as concepções atualizadas de sujeito como constituido pelo/do discurso.

Nesse ponto, é nos possível recorrer ao conceito de identidade, a fim de apresentarmos as possíveis conotações políticas da linguagem que compõem o universo formado pelas ideologias de consumo, que, por sua vez, são reforçadas pelo marketing que trabalha em conjunto com as representações midiáticas dentro do sistema atual (DALY, 1984): "a abordagem discursiva vê a identificação como uma construção, como um processo nunca completado - como algo sempre 'em processo"' (HALL, 2000, p. 106).

Hall (apud SILVA, 2000), aponta que o mecanismo pelo qual passa o indivíduo em sua relação à subjetivação identitária trata-se, de acordo com a compreensão lacaniana, de um falso reconhecimento. Subsequentemente, este autor apresenta uma crítica ao trabalho geral de Foucault que teria a ver com a suposta dificuldade deste em teorizar a resistência ou o que viria a problematizar a inserção dos indivíduos às posições-de-sujeitos construídas pelos/nos discursos, como 'corpos dóceis'. Para Hall (2000), Foucault não teoriza sobre as razões que levam esses 'corpos dóceis' a se prontificarem a ocupar essas posições dóceis, o que nos leva, por outro lado, indiretamente a Hall (2000), que postula que os estudos da identidade não dependem restritamente da psicanálise. Portanto, Foucault (2011), na compreensão do indivíduo, não toma a apreensão do humano fora de sua historicização, pois 
quando se trata da compreensão do ser na concretude de sua realidade social, este autor aponta um fato: o homem, enquanto ser social, não pode ser compreendido fora do tempo-espaço de seu contexto sóciopraxiológico, ou seja, fora das redes capilares das relações de força ou poder, pois, nessa condição, o ser ocupa sempre uma posição sóciodiscursiva com a qual ele constrói seus 'lapsos' identitários.

Joana Pinto (2017), por intermédio dos estudos de Butler, articula os conceitos das relações de poder em Foucault, trazendo à tona a relação entre linguagem e identidade, em que a distinção habitual entre o corpo e a própria linguagem é dirimida, já que diante dos problemas da identidade, ato de fala e ato de corpo compõem um único ato performativo, ou seja, em uma concepção não homogênea da linguagem, mesmo que o corpo anteveja o sujeito, este e aquela estão amalgamados em performativos. Esta autora considera que as identidades funcionam como efeito dos atos de fala que podem se estruturar binária e hierarquizadamente, o que leva a necessidade de cautela para que a identidade, como parâmetro recente de definição do sujeito, não recaia em sua normatização por uma concepção tradicional de identidade. Pinto (2017) enfatiza a necessidade de um conceito de identidade abrangente, reconhecendo que a repetição das ações é o que constrói as identidades, na medida em que a linguagem é parte do lugar social de onde se fala, por ser simultânea à própria identidade que depende da repetição dos atos (de fala) sustentados pela/na linguagem.

\section{Agência}

Martins Ferreira (2017) nos provê de conceitos sobre como as nomenclaturas de indivíduo, sujeito, ator (social), protagonista e agente (agência), estão em diálogo com estudos sociais e estudos linguísticos.

A autora inicia sua argumentação chamando a atenção para a concepção de Touraine (2006) sobre sujeito como existencial e de vontade, capaz de ações transformadoras, já que é possuidor de criatividade, mas contraria a posição sociológica de Touraine, que privilegia o sujeito em detrimento do indivíduo, até por que "não podemos identificar o indivíduo como uma tábua rasa, em que o social não toca (...) nem podemos negar ao sujeito a subjetividade reflexiva e pessoal” (p. 4). Vai também de encontro à posição de Bourdieu (1984) que, sob o condicionamento do habitus, posiciona o sujeito "cativo ao sistema" Se, de um lado, para Bourdieu (1984), diz a autora, a linguagem 
comum seria inoperante, na perspectiva da agência, este sujeito 'cativo' para ser verdadeiramente agente precisaria se apropriar de uma linguagem operacional e que, nas relações sociais, o torne instrumento de poder e dominação.

Por outro lado, Touraine (2006) vê no sujeito criativo individual o potencial para mudança; por ser um agente, o sujeito-ator social pode se tornar um protagonista de seu projeto de ação. E se este sujeito tourainiano é agente, ator social e protagonista, na perspectiva de nosso trabalho, ele pode agenciar a própria transformação dos hábitos de consumo predatório que, por sua vez, precisa ser aderida pela sociedade civil, gerando uma avalanche de força a setores público e privado, pressão que representaria valores éticos de cuidado com o outro e com o mundo.

No que tange à posição do sujeito em estudos da linguagem, Martins Ferreira (2017) considera a linguagem em sua condição de prática social e de natureza performativa. Apesar de abordar o sujeito faircloughiano como portador de possibilidades de mudanças sociais, tende sua opinião para o sujeito austiniano, um sujeito individual que existe pelos atos de fala que profere, mesmo que contextualizado dentro de normas institucionais tal como o exemplo: o juiz tem a autoridade de proferir atos de fala da ordem de julgar, de casar, enquanto o padre de batizar, casar... Enquanto a posição faircloughiana do sujeito do discurso impossibilita uma autonomia da agência, a de Austin, pelo caráter performativo da linguagem se sobressai, o que possibilita um sujeito individual atuante - enquanto ator e agente.

Assumindo um sujeito agente individual, tanto na perspectiva de Touraine (2006) quanto de Austin (1975), como tal, o indivíduo pode se desembaraçar das significações e práticas hegemônicas, como no caso da ideologia consumista predatória, e iniciar um processo de transformação social que se dá com a coletivização das práticas protagonistas individuais que obrigue e/ou pressione o Estado e as empresas a se ajustarem a uma produção pautada na valorização do ser humano e da natureza. Nessa discussão de articulação híbrida social + linguagem -, as práticas individuais sustentáveis podem ter uma margem de horizonte transformacional, ao serem assumidas por um número suficiente de pessoas que inaugurem uma etapa de cuidados para com a outridade. 


\section{Sustentabilidade}

\section{Sustentabilidade e seu(s) sentido(s)}

A definição que tomamos de sustentabilidade provem de Boff(2015) que a toma como resultado das práticas humanas em prol da manutenção das comunidades de vidas e ecossistemas, assim como do provimento de recursos naturais para as demandas atuais e futuras das sociedades.

Nas palavras do autor, sustentabilidade é:

O conjunto dos processos e ações que se destinam a manter a vitalidade e a integridade da Mãe Terra, a preservação de seus ecossistemas com todos os elementos físicos, químicos e ecológicos que possibilitam a existência e reprodução da vida, o atendimento das necessidades da presente e das futuras gerações, e a continuidade, a expanção e a realização das potencialidades da civilização humana em suas várias expressões (BOFF, 2015, p. 14).

Boff (2015) partilha dois sentidos - passivo e ativo - no conceito de sustentabilidade. Inciando pela raiz etimológica do termo sustentabilidade sustentare em latim (sustentar, em português), o sentido passivo de sustentabilidade seria um processo inerente aos sistemas de vida em gerir sua própria sobrevivência, através do equilibrío e conservação feita de si para si; contudo, para que o sentido ativo se concretize, as ações humanas devem gerar as condições da natureza para manter sua própria preservação:

O sentido ativo enfatiza a ação feita de fora para consersar, manter, proteger, nutrir, alimentar, fazer properar, subsistir, viver. No dialeto ecológico isso significa: sustentabilidade representa os procedimentos que tomamos para permitir que a Terra e seus biomas se mantenham vivos, protegidos, alimentados de nutrientes a ponto de estarem sempre bem conservados e à altura dos risco que possam advir (BOFF, 2015, p. 32).

A propiciação de tais condições depende principalmente de atitudes que evitem agravar ainda mais as situações dos ecosssitemas, sem darlhes tempo de se regenerarem, o que nos leva a falar da problemática da ideologia propagada pelo consumo. 


\section{Ideologia do consumo}

Ao adentramos na questão do consumismo, algumas prerrogativas esclarecedoras se fazem necessárias. Enquanto Boff (2009; 2015) anexa consumo à problemática ambientalista predatória devido ao crescimento econômico, o consumo pode ser entendido como signo de distinção (ALLĖRES, 2006), ou seja, a aproximação dos bens "substitutivos" em relação aos "originais" devido à crescente necessidade das classes superiores de buscar sempre novos signos de distinção. Já Bourdieu (1994) reforça esta questão de distinção ao postular que as escolhas no consumo tornam-se um dos mecanismos fundamentais de diferenciação, inclusão e exclusão social, senão de um "estilo de vida", que não necessariamente uma mera escolha individual. E não é à toa que Baudrillard postula:

(...) nunca se consume o objeto em si (no seu valor de suo) - os objetos (no sentido lato) manipulam-se sempre como signos que distinguem um indivíduo, quer filiando-o no próprio grupo tomado como referência ideal, quer demarcando-o do respectivo grupo por referência a um grupo de estatuto superior (...) (2005, p.60).

Mary Douglas e Baron Isherwood (2009) defendem a ideia de consumo sob a perspectiva cultural-econômica, na medida em que "todas as posses materiais carregam significação social” e são comunicadoras (2009, p. 105), ou melhor, a utilidade de um bem reproduz valorizações dentro de um quadro cultural. Como diz McCracken:

(...) o consumo é moldado, dirigido e constrangido em todos os seus aspectos por considerações sulturais. (...) Os bens de consumo nos quais o consumidor desperdiça tempo, atenção e renda são carregados de significado cultural (...) para expressar categorias e princípios culturais, cultivar ideias, criar e sustentar estilos de vida, construir noções de si e criar (e sobreviver a) mudanças sociais (2003, p.11).

E na medida em que o "estilo de vida" não é um conjunto fixo de disposições, mas uma escolha ativa (Featherstone, 1995), a nossa proposta de uma agência sustentável ganha força argumentativa. E daí percebermos que a responsabilidade pelo meio ambiente surge de um acordo mútuo entre o setor público (governo) e o privado (empresas e corporações), quando pressionados pela sociedade civil, uma vez 
que a transição para uma mentalidade sustentável de mercado não irá acontecer enquanto o lucro for a única meta das práticas sociais e o crescimento infinito continuar um ideal dos países.

Uma governança internacional se insurgirá se for ocasionada pela força da organização social balizada pelo o que chamaremos de uma agência sustentável, que advoga novas formas de produção e consumo para uma nova era ecológica.

Consideramos que, pela agência sustentável, podemos possibilitar o surgimento de práticas ecológicas individuais que forcem as práticas propostas pelos setores público e privado, como sustentáveis, a serem verdadeiramente sustentáveis e não apenas como agregação de valor aos produtos. A pressão sobre empresas diversas pode garantir que essas se engajem em produções sustentáveis mais coerentes em seus sentidos de valorização do ambiente e da sociedade, uma vez que uma prática sustentável em nível apenas produtivo ${ }^{5}$ não pode se resumir genericamente a uma única etapa de toda a cadeia de produção, onde marcas seriam produzidas em um processo supostamente sustentável, mas que, na maioria das vezes, não o são de fato (BOFF, 2015).

Essa agência, diante da ideologia de consumo irrestrito deve surgir do ensinamento de Daly (1984, p.94) quando diz que "os países subdesenvolvidos terão de revisar e baixar as expectativas em relação ao crescimento", já que o índice de $\mathrm{PNB}^{6}$ não possibilita perceber que encontra-se um consumo alto de supérfluos ${ }^{7}$ entre as classes mais elevadas mesmo que seja o principal objetivo do crescimento econômico (DALY, 1984). Na perspectiva de Boff (2015), seja diante da produção ética ou seja da predatória, a produção predatória está na maior parte dos produtos e, por isso, sugere o fim do fetiche de crescimento e a emergência de um processo de educação social que contorne tal tipo de consumismo.

Diante disso, pode-se falar de uma agência para um consumo reciclável ou até frugal, ao modo, por exemplo, da ética andina do bem viver, apontada por Boff (2015), uma vez que a transformação no consumo leva naturalmente a uma pressão diante das formas de produção, quando esse consumo 'conservatório' se torna uma força coletiva a partir da generalização de práticas individuais.

5 Ver nota 3.

$6 \mathrm{PNB}=$ Produto Nacional Bruto.

7 Ver nota 3. 
A agência sustentável diante do consumo é uma nova relação com o outro e a natureza, que, mesmo pontual (individual), ao se generalizar ('coletivizar'), pode forçar a construção de uma agenda global conciliadora entre produção e sustentabilidade - comprometimento do sistema industrial com mobilização social de consumo ético.

\section{Rio+20}

Para proliferar uma postura crítica sobre os diferentes modos representativos de uma agência sustentável, a análise de formas textuais do discurso oficial de abertura da conferência Rio+20 nos faria compreender diferentes maneiras de se apropriar da realidade e diferentes pontos de vista sobre os problemas ecológicos, investidos de diferentes sentidos ideológicos.

Um dos aspectos mais inovadores do discurso oficial é sugerir a necessidade de submeter o crescimento econômico ao princípio da distribuição:

Desenvolvimento sustentável implica crescimento da economia, para que se possa distribuir riqueza. Significa criação de empregos formais e expansão da renda dos trabalhadores. Significa distribuição de renda para pôr fim à miséria e reduzir a pobreza. Significa garantir acesso à educação, à saúde, segurança pública e todos os serviços necessários ao bem-estar da cidadania plena da população. Significa tornar nossas cidades cada vez mais sustentáveis. Significa reduzir o desmatamento. Significa usar, de forma sustentável, nossa biodiversidade e proteger nossos rios e florestas. Significa gerar energia limpa. (BRASIL, 2012)

Vários estudiosos, incluindo Veiga (2013), veem pouco benefício do crescimento econômico diante das desigualdades, já que, como pode ser percebido, a partir de certa renda, se considerarmos a elevação do bemestar, o crescimento econômico satisfaz apenas o consumo predatório, necessitando obrigatoriamente ser corrigido pela distribuição mais igualitária. Porém, a visão econômica tradicional sobrepõe o crescimento à distribuição (VEIGA, 2013). Acontece que em sistemas mais desiguais de distribuição ${ }^{8}$, percebe-se uma situação crítica diante das questões socioambientais cruciais.

8 Não estamos levando em conta a situação de países africanos que necessitam de consumo, seja qual a classificação que receba - produtiva ou predatória -, para que a desigualdade e a miséria sejam, no mínimo, aliviadas. 
Como aponta Veiga (2013), a partir de pesquisas especializadas, notou-se que há uma relação entre menor desigualdade que leva a menor consumismo, maior reciclagem e maior ajuda a países pobres. $\mathrm{O}$ que nos faz deduzir que quanto maior a desigualdade, maior será a busca pelo controle das fontes de poder daquela sociedade, o que ocasiona um crescente consumismo, já que produtos podem funcionar como elementos de atribuição social de poder, mesmo que seja apenas no plano ideológico. Assim, nos parece que quanto maior a esperança de controle das fontes de poder, em sistemas desiguais de distribuição das riquezas produzidas, mas facilmente se alastra a ideologia do consumo predatório, já que a desigualdade não é vista como impedimento para um desenvolvimento socioeconômico qualitativo.

Outro ponto que queremos trazer a baila é a indicação, feita pelo discurso oficial, que devemos nos mobilizar diante da situação drástica dos ecossistemas:

A tarefa que nos impõe a Rio+20 é desencadear o movimento de renovação de ideias e de processos, absolutamente necessários para enfrentarmos os dias difíceis em que hoje vive ampla parte da humanidade. Sabemos que o custo da inação será maior que o das medidas necessárias, por mais que essas provoquem resistências e se revelem politicamente trabalhosas. (BRASIL, 2012)

Boff (2015), que sempre se engaja nas discussões diante do panorama socioambiental atual, também expressa sua preocupação com a inércia, como fator maléfico diante da atualidade. Ou seja, apenas ler as notícias, não agenciar uma atitude, permanecer com um comportamento indiferente corresponderia de certa forma a uma atitude predatória socioambiental.

Especificamente, quanto às considerações possíveis sobre agência no discurso oficial, queríamos considerar sua aderência às decisões estabelecidas na conferência Rio-92, realizada 20 anos antes:

A Conferência do Rio 1992 estabeleceu um consenso mundial em torno do desenvolvimento sustentável e nos deu os princípios sobre os quais temos de atuar. A afirmação de que os seres humanos estão no centro das preocupações com o desenvolvimento sustentável colocou a erradicação da pobreza como requisito indispensável da ação política. Esse princípio ligou, de forma indissolúvel, a agenda ambiental à necessidade de realizar reformas estruturais, capazes de incluir as 
multidões de homens e mulheres e crianças que viviam e ainda vivem na pobreza e exclusão. (BRASIL, 2012)

Essa aderência implica a inclusão dos indivíduos no desenvolvimento sustentável, haja vista a Carta da Terra. Tal é tão enfatizada no evento de 1992 quanto no do discurso oficial Rio+20:

[Na Conferência do Rio 1992] Consagrou-se o princípio de que na construção do desenvolvimento sustentável, os Estados têm responsabilidades comuns, porém, diferenciadas. E reconheceu-se a necessidade de eliminar padrões insustentáveis de produção e consumo (BRASIL, 2012).

Nesse fragmento fica sugerida a importância da mudança de costumes, que pode gerar a transformação nos modelos de consumo e, posteriormente, nos de produção, já que a sustentabilidade "evoca a necessidade que profundas transformações” (VEIGA, 2013, p. 10).

Mesmo com os compromissos feitos na Rio+20, muitos pesquisadores apontam o fracasso do evento em termos de avanço para uma aliança global ambiental. E mesmo diante dos resultados alcançados, ressaltamos a importância da força política do evento e da sociedade diante da realidade ecológica.

\section{Considerações Finais}

Sejam quais forem as linhas interdisciplinares teóricas que se entrecruzam, propusemos a tomada de uma postura de resistência e agenciamento diante do discurso mercadológico, e a conciliação entre paradigma ocidental dominante de pensamento e epistemologias do sul (SANTOS, 2009) - locus considerado de culturas diversas e subalternas -, em que as agências possam proliferar fora das relações de poder.

Para Boaventura de Santos (2009), o pensamento ocidental, em uma pretensa atitude cientificista, se acomodou em um restrito princípio epistemológico e acabou por ignorar, a partir de investimentos colonizantes, as demais formas de conceber o mundo e seus significados, o que representou uma redução significativa da diversidade cultural, a partir de uma auto enunciação de superioridade civilizatória, na qual nunca poderemos aprender, e.g., com práticas alternativas como as dos povos andinos, no aspecto ecológico do bem viver (BOFF, 2015). 
A conciliação de epistemologias pode contribuir com formação de reflexões críticas sobre as consequências e efeitos das práticas humanas sobre o meio-ambiente, inclusive compreender como a linguagem mobiliza (e é mobilizada) problemáticas socioambientais.

Ratificamos a indispensabilidade de uma governança global para a sustentabilidade geral, ou seja, a transformação do consumo por parte da sociedade que pode forçar mudanças empresariais de produção, como no caso dos problemas da camada de ozônio em que os consumidores pressionaram as empresas de tal forma que acarretou pressão sobre o governo Estados Unidos a se engajar na criação do Programa das Nações Unidas para o Meio Ambiente (PNUMA) ${ }^{9}$. A atuação do PNUMA teve uma grande contribuição, no contexto relacionado à camada de ozônio, que reflete um êxito tanto na governança global diante dos problemas ecológicos, quanto um favorecimento de tomada de medidas mais efetivas.

Com este exemplo de agência - PNUMA -, outras agências podem emergir, tais como: comportamentos individuais que teriam seu valor potencializado pela pressão que exerceriam em prol de acordos internacionais; força da mobilização social que reduziria uma produção predatória; e setores público e privado que tomariam medidas efetivas diante de problemas ambientais.

Na e pela agência, uma vez aplicada ao contexto do desenvolvimento sustentável e a uma provável revolução no consumo, estudiosos e pesquisadores têm um papel crucial, o de fazer a sociedade perceber o poder que ela tem em mãos e que pode ser usado em prol da manutenção da vida como um todo.

\section{REFERÊNCIAS BIBLIOGRÁFICAS}

AUSTIN, J.L. How to do things with words. Second Edition Oxford: Oxford University Press, 1975, UK. 168p.

9 Veiga (2013) aponta que a Conferência de Estocolmo serviu como contexto de surgimento do PNUMA, cujo maior interesse em definir seu status, estrutura e modo de financiamento veio dos Estados Unidos que articulou para que a responsabilidade das questões ambientais do PNUMA fossem associadas à Secretaria Geral da ONU, o que os críticos veem como um empecilho para sua atuação efetiva na construção da governança global em prol da sustentabilidade. Posteriormente, mesmo com a inclusão da pauta estrutural da ONU na Rio+20, o PNUMA não foi transformado em agência especializada, mesmo contra sugestões de vários países e estudiosos. 
BAUDRILLARD. J. A sociedade de consumo. Trad. de Arthur Mourão. isboa: Edições 70, 2005. 213p.

BOFF, Leonardo. A opção Terra: a solução para a Terra não cai do céu. Rio de Janeiro: Record, 2009. 224p.

2015. 209p.

Sustentabilidade: o que é, o que não é. 4a. ed. Petrópolis/RJ: Vozes,

BOURDIEU,P. Homo academicus. Paris: Minuit, 1984. 302p.

DALY, Herman. A economia do século XXI. Trad. de Renato Souza. Porto Alegre, Mercado Aberto, 1984. 120p.

DOUGLAS, M. e ISHERWOOD, B. O mundo dos bem - para uma antropologia do consumo. Trad. de Plínio Dentizien. Rio de Janeiro: UFRJ, 2009. 304p.

FAIRCLOUGH, Norman. Discurso e mudança social. Trad. de Izabel Magalhães (org.) Brasília: Ed. UNB, 2008. 320p.

FEATHERSTONE, M. Cultura do consumo e pós-modernismo. Trad. de Julio Assis Simão. São Paulo: Studio Nobel, 1995. 223p.

FERREIRA, Raimundo R. A guerra na língua - as representações do "11 de setembro" na mídia e no discurso oficial. Campinas/SP: [s.n.], 2005. Tese de doutorado Universidade Estadual de Campinas, Instituto de Estudos da Linguagem.

FOUCAULT, Michel. Microfísica do poder. Org. e Trad. de Roberto Machado. Rio de Janeiro: Edições Graal, 2011. 432p.

GUIMARAES, Roberto P.; FOUNTOURA, Y.S. dos R. "Rio+20 ou Rio-20? Crônica de um fracasso anunciado”. Ambiente \& Sociedade. v. XV, n. 3. São Paulo, p. 19-39, set-dez - 2012 .

HALL, Stuart. “Quem precisa de identidade?”. In: SILVA, Tomaz T. da (org.); HALL, Stuart; WOODWARD, Kathryn. Identidade e diferença: a perspectiva dos estudos culturais. Petrópolis, RJ: Vozes, 2000, p. 103-133.

MCCRAKEN, G. Cultura de consumo: novas abordagens ao caráter simbólico dos bens e das atividades de consumo. Trad. de Fernando Eugênio. Rio de Janeiro: MAUAD, 2003. 208p.

MARTINS FERREIRA, Dina. "Do semelhante ao mesmo, do diferente ao semelhante - sujeito, ator, agente e protagonismo na linguagem”. Revista Brasileira de Linguística Aplicada/RBLA, v. 17, n. 4, p. 619-640, 2017. 
PINTO, Joana Plaza. Conexões teóricas entre performatividade, corpo e identidade. D.E.L.T.A., v. 23, n.1, 1-26, 2017.

RAJAGOPALAN, Kanavillil. Por uma linguística crítica: linguagem, identidade e a questão ética. São Paulo: Parábola Editorial, 2003. 144p.

ROCHA, E. Apresentação: In: DOUBLAS, M. e ISHERWOOD, B. O mundo dos bens - para uma antropologia do consumo. Rio de Janeiro: UFRJ, 2009, p.7-18.

SANTOS, Boaventura de Sousa. "Para além do pensamento abissal: das linhas globais a uma ecologia dos saberes". In: SANTOS, Boaventura de Sousa; MENESES, Maria Paula (Orgs.); [et al.]. Epistemologias do sul. Coimbra: Almedina, 2009, p. 23-72.

SLATER, D. Cultura do consumo e modernidade. Trad. Dinah de Abreu Azevedo. São Paulo: Nobel, 2001. 216p.

TOURAINE, A. El sujeto. Um nuevo paradigma para compreender el mundo de hoy. Traducción María Tabuyo y Agustín L. Tobajas. Buenos Aires: Paidós, 2006. 272p.

VEIGA, José Eli da. A desgovernança mundial da sustentabilidade. São Paulo: Editora 34, 2013. 152p. 